\title{
Evidence Gaps and Challenges in the Fight Against COVID-I9 in Africa: Scoping Review of the Ethiopian Experience
}

\author{
Esayas Kebede Gudina (iD) 1,2 \\ Matthias Siebeck (iD) ${ }^{2,3}$ \\ Million Tesfaye Eshete ${ }^{2,4}$ \\ 'Department of Internal Medicine, \\ Institute of Health, Jimma University, \\ Jimma, Ethiopia; ${ }^{2}$ Center for International \\ Health at LMU, University Hospital, LMU, \\ Munich, Germany; ${ }^{3}$ Institute of Medical \\ Education, University Hospital, LMU, \\ Munich, Germany; ${ }^{4}$ Department of \\ Anesthesiology, Institute of Health, Jimma \\ University, Jimma, Ethiopia
}

Background: Ethiopia, like many African countries, took immediate actions to contain the coronavirus disease (COVID-19) outbreak and its impacts. However, the pandemic control measures were not guided by robust local evidence and not tailored to national contexts. In this review, we aimed to evaluate the evidence gaps and challenges of COVID-19 control measures in Ethiopia during the early months of the pandemic.

Design: Scoping Review.

Data Source: Searches were conducted in PubMed, LitCovid, Web of Sciences, Embase, MedRx, ChemRxiv, BioRx, and Google Scholar.

Eligibility Criteria: Peer-reviewed or pre-print original research articles on COVID-19 from Ethiopia during a period of January 1, 2020 and October 10, 2020 were included in this review.

Results: Of 573 articles found, 64 were eligible for inclusion. However, only 25 of them were peer-reviewed; 78\% (50/64) were based on cross-sectional descriptive studies. Most of the studies focused on human behavior and healthcare system; only 13 articles addressed epidemiology and clinical spectrum of COVID-19. The studies have revealed a good level of awareness and a favorable attitude by community and healthcare workers (HCWs) towards COVID-19 and its control. However, the practices of infection prevention were found to be low among HCWs and the community. The outbreak unfolded at a slower rate than initially feared but the impact of the counter measures against COVID-19 on the delivery of essential healthcare services was felt more than the direct impact of the pandemic. Moreover, the actions taken by the country did not appear to be tailored to the pattern of the outbreak and existing local evidence. The overall number of published COVID-19-related scientific articles from Ethiopia during the review period was found to be limited.

Conclusion: COVID-19 control in Ethiopia was challenged by lack of robust local scientific evidence, and the pandemic control measures were not adapted to local context and the outbreak patterns. Thus, Ethiopia and other African countries should design culturally sensitive and locally acceptable public health interventions for COVID-19 and potential future outbreaks based on locally generated scientific evidence.

Keywords: COVID-19, Ethiopia, pandemic, preparedness, research, scoping review

\section{Plain Language Summary}

Africa in general and Ethiopia, in particular, contributed very little to COVID-19 research. As a result, most of the actions taken by the continent to curtail the pandemic were trial-anderror approaches. In this review, we conducted the first complete overview of the evidence gap and body of literature from Ethiopia on COVID-19. We tried to assess how the available
Correspondence: Esayas Kebede Gudina Email esakgd@gmail.com 
evidence and the pattern of the outbreak affected the countermeasures taken by the country. With our review, we found that Ethiopia generated limited local scientific evidence. Moreover, the actions taken by the country were not tailored to the outbreak pattern and local contexts. This created a vicious circle of early actions that led to serious collateral damage which in turn forced the government to relax the restrictions later on. As a result, Ethiopia, like many African countries suffered from high spread of the disease after relaxing the interventions. The findings in our review highlight the values of locally generated evidence and context-specific actions in the pandemic control. Thus, Africa in general and Ethiopia in particular should invest in generating and making proper use of local evidence in the control of existing and future outbreaks and pandemic diseases.

\section{Introduction}

An outbreak of a new infectious disease is a global concern no matter where it occurs because of the risk of its spread to other countries. ${ }^{1}$ Data and information sharing between countries are essential to contain the spread of an outbreak; and generating local data is essential to tailor targeted actions and sustain the control measures. ${ }^{2,3}$

China tried to cut off Wuhan, the epicenter of the outbreak, from the rest of the country and implemented a complete lockdown to curb the spread of the infection during the early months. That helped the country control the outbreak within a few months., ${ }^{4,5}$ Almost all other countries tried to copy these approaches but only a few managed China-like success. ${ }^{6}$

Every country has its peculiarities in terms of population characteristics, environment, and resources to manage its healthcare system. Thus, any effort to contain an outbreak of any disease should put into consideration the pattern of local disease transmission, the capabilities of its healthcare system, the feasibility of actions taken, and its population characteristics. ${ }^{7}$ Hence, any mitigation strategies destined to succeed should be customized to domestic needs based on scientific evidence generated locally. ${ }^{8}$

Like many African countries, Ethiopia took immediate actions to contain the coronavirus disease 2019 (COVID-19) outbreak during the early months of the pandemic. However, the pandemic control initiatives by the country were challenged by multiple factors. ${ }^{9,10}$ The country lifted most of its COVID-19-related restrictions in September 2020 despite the steady increase in the number of cases and COVID-19related deaths by then. ${ }^{11}$ On top of that, there has been widespread public fatigue, reluctance to implement preventive measures, and conspiracy beliefs distracting the public. ${ }^{12}$
Actions taken to curtail the pandemic in Africa were mostly copied from elsewhere and never tested locally. ${ }^{13}$ Although most of them were known to be effective to control the pandemic, they might severely affect lives and livelihood in economically constrained settings. These in turn may affect the communities' compliance to implement the recommended actions. ${ }^{14}$

It is thus essential to strengthen the quality of national data collection, handling and management procedures regarding COVID-19 to produce evidence that will help design contextualized actions. ${ }^{15}$ The overall aim of this review was to identify knowledge gaps and scope a body of literature about COVID-19 in the Ethiopian context during the early phase of the pandemic.

\section{Methods}

In this scoping review, we tried to (i) assess the existing scientific evidence on COVID-19 from Ethiopia; (ii) compare peer-reviewed scientific evidence on COVID-19 from Ethiopia against countries from Africa that were highly affected by COVID-19 and/or comparable population size; and (iii) evaluate if the action taken by the Government of Ethiopia was guided by scientific evidence and disease pattern.

\section{Review of Existing Scientific Knowledge}

The review was performed based on the methods described by Arksey and O'Malley ${ }^{16}$ by implementing the five stages of the scoping review process: (i) identifying the research question; (ii) identifying relevant studies; (iii) study selection; (iv) charting the data; and (v) collating, summarizing and analyzing the included literature. We have reported this review following the guidance in the Preferred Reporting Items for Systematic Reviews and Meta-Analyses extension for Scoping Reviews (PRISMAScR). ${ }^{17}$

\section{Identifying the Research Question}

This review was conducted to answer the following research questions: (i) What were the scopes, nature, and quality of local scientific evidence on COVID-19 from Ethiopia? (ii) Were the national actions against COVID19 in Ethiopia guided by local scientific evidence and disease patterns? (iii) How did Ethiopia fare in terms of locally generated scientific evidence compared with other African countries with a comparable population and/or COVID-19 outbreak patterns? We defined "local scientific evidence" as any research conducted within Ethiopian 
territory and focusing mainly on COVID-19 in Ethiopia. The setting included community, healthcare facilities, and healthcare systems.

\section{Identifying Relevant Studies (Search Strategy)}

We performed a comprehensive literature search aimed to find both published and unpublished studies conducted from January 1, 2020 to October 10, 2020. All relevant articles were identified through a systematic search of MEDLINE via PubMed and LitCovid, Web of Sciences, and Embase. Pre-print servers such as MedRx, ChemRxiv and BioRx were also searched to include non-peerreviewed articles. The following search terms were used to retrieve articles: "COVID-19" OR "SARS-CoV-2" OR "2019 novel coronavirus" OR "2019-nCoV” OR "novel coronavirus" AND "Ethiopia". The search for unpublished studies/gray literature was performed in Google Scholar and through the review of reference lists and input of content experts. All literatures that met the keywords were included in this review. The search strategies used for PubMed and gray literatures are detailed in Supplementary Material as Annex - I.

\section{Study Selection (Inclusion and Exclusion Criteria)}

All studies focusing on COVID-19 in Ethiopia during the specified period were included. There was no exclusion based on the type of participants (individual patients, community, healthcare workers, and healthcare system). Only original research published as peer-reviewed articles or pre-print versions during the period of January 1, 2020 and October 10, 2020 were included in this review. However, we did not exclude articles based on the study design. Only studies published in the English language were included.

Identified articles were screened for duplications. Two independent reviewers screened the articles using titles and abstracts based on the inclusion criteria for the review. Full texts of potentially eligible studies were retrieved and assessed in detail against the inclusion criteria. Full-text studies that did not meet the inclusion criteria were excluded. Any disagreements that arose between the reviewers were resolved through discussion and consensus. The search of the literature was conducted from October 15, 2020 to November 30, 2020. The results of the search were reported in full in the final review and presented in a Preferred Reporting Items for Systematic Reviews and Meta-analyses (PRISMA) flow diagram.

\section{Assessment of Methodological Quality}

Studies meeting the inclusion criteria were assessed for methodological validity before inclusion in the review using standardized critical appraisal instruments from Joanna Briggs Institute for all types of studies. All studies regardless of their methodological qualities underwent data extraction and synthesis.

\section{Data Extraction, Synthesis, Analysis, and Presentation of Key Findings}

We conducted a qualitative synthesis of the characteristics of the included literatures. We described the source where we found the article, publication year, type of article/study, and topic of article/study or guidance/guideline on COVID-19 to examine the existing gaps in research. Data from included articles were extracted using a standardized data extraction format from the Joanna Briggs Institute.

We categorized the literatures based on their focuses and key findings into (A) Knowledge, attitude, and practice about COVID-19 and its prevention; (B) Disease epidemiology and clinical profile of the cases; (C) Mental health issues during COVID-19 pandemic; (D) Preparedness for COVID-19 control; (E) Impacts on essential healthcare; and (F) Violence against women during COVID-19 lockdown. Findings were synthesized only descriptively and presented narratively and summarized in proportions and frequencies in tables. The extracted data were summarized into a table using the following contents: author, year, and title; source/journal; aims; study design; participants; and key findings (Annex - II in Supplementary Material).

\section{Results}

\section{Study Inclusion}

The initial comprehensive literature search yielded 573 articles. Of these, 105 were excluded due to duplications. From the remaining 468 articles, 280 were excluded after reviewing their titles and abstracts confirmed nonrelevance to this review. With further scrutiny, 100 of the remaining 188 articles were excluded after reading the abstracts. The remaining 88 articles were retrieved for fulltext review (Figure 1). Among these, 64 articles were included in the current narrative synthesis (Annex - II in 


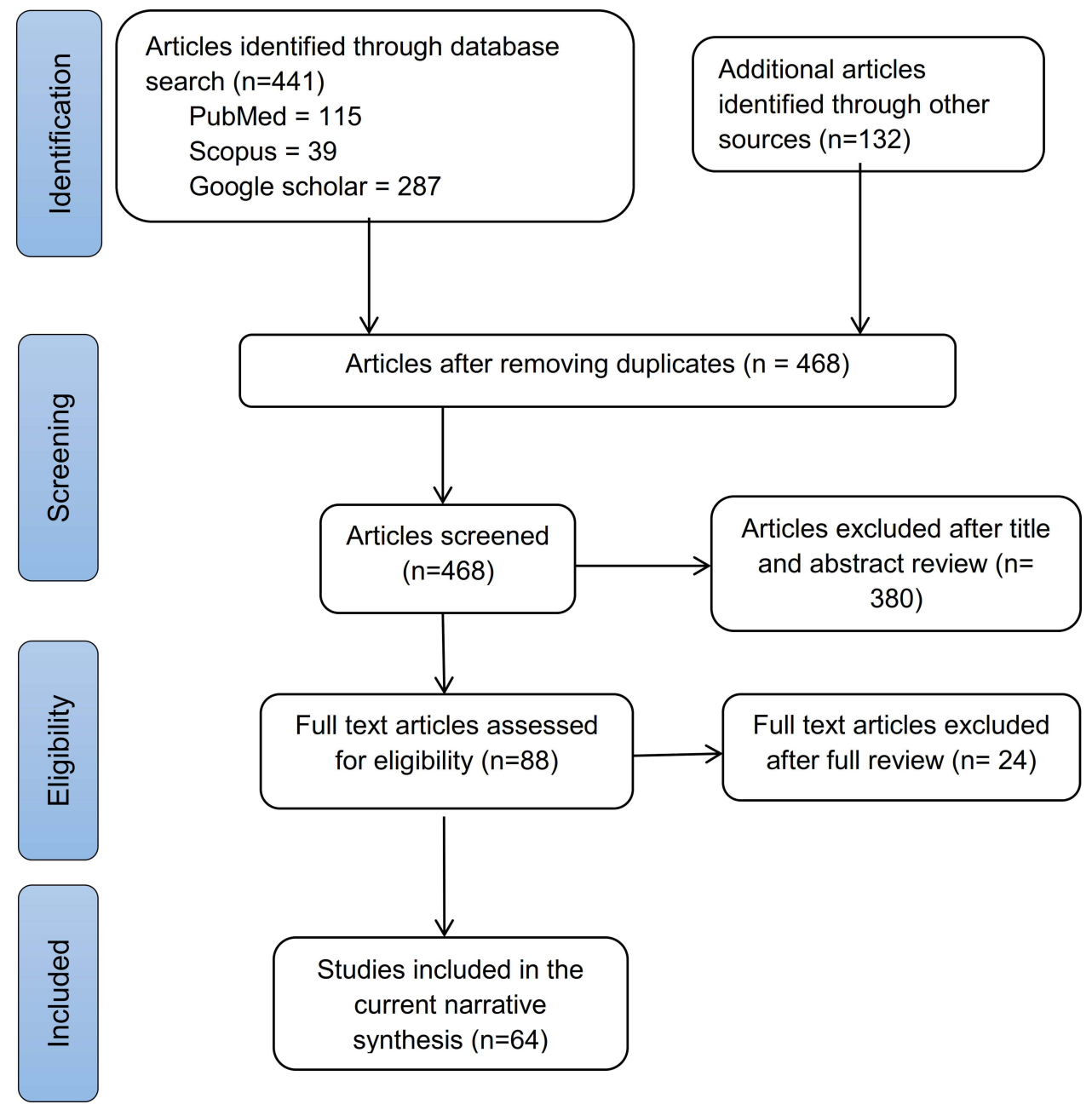

Figure I PRISMA flow diagram of study selection and inclusion process.

Note: Adapted from Tricco AC, Lillie E, Zarin W, et al.PRISMA extension for scoping reviews (PRISMA-ScR): checklist and explanation. Ann Intern Med. 20I8; 169(7):467473. doi: $10.7326 / \mathrm{M} 18-0850 .^{17}$

Supplementary Material) and 24 were excluded for various reasons (Annex - III in Supplementary Material).

\section{Characteristics of Included Studies}

Only 25 of the included full-text articles were published in peer-reviewed journals; ${ }^{18-42}$ the rest 39 were preprints at the time of this review ${ }^{43-81}$ (Annex - II in Supplementary material). Most, 50 (78\%), of the included studies were cross-sectional descriptive studies. The 64 articles were thematized into six categories based on their major focus areas.

\section{Knowledge, Attitude and Practice (KAP) About COVID-19 and Its Prevention}

Nearly half $(n=30)$ of the articles fell into this category. A total of about 20,000 participants, comprised of community and healthcare workers, participated in these studies. More than $95 \%$ of the participants reported to have repeatedly heard about COVID-19 and its prevention methods. ${ }^{21,22,69}$ As a result, the perceived knowledge level was found to be high even during the first few weeks of the outbreak among $\mathrm{HCWs}^{21,28,43,48,49}$ and the community. ${ }^{19,20,22,23,45,73}$ HCWs in general ${ }^{27,43,51}$ and those working at university hospitals in particular ${ }^{49}$ showed a favorable attitude towards COVID-19 and its prevention. The trend was similar among community participants. $^{45,56}$

However, the proper infection prevention and control (IPC) practices were low for both HCWs and the community. While self-reported practices of prevention methods were acceptable (62-100\%) among $\mathrm{HCWs},{ }^{26,28,48,49,51}$ it was found to be low $(<50 \%)$ among the general public. $^{22,44,52,54-56,58,59}$ 
Concerning specific prevention practices, most of the recommended methods were poorly implemented by HCWs and the community. For instance, mask use at workplaces and public gatherings was reported to be low. ${ }^{28,29,47,56,58}$ Only a few reported avoiding social gatherings and crowded settings ${ }^{58}$ and practicing social distancing. ${ }^{45,47,56}$ Most importantly, $21.2 \%$ of the participants opposed the wearing of face masks ${ }^{23}$ and $28.3 \%$ had low intention to carry out those prevention measures. ${ }^{57}$ Even though HCWs and community participants reported frequent hand washing practice, ${ }^{24,25,52}$ only $16.3 \%$ of HCWs were observed to follow the correct sequence in hand washing. ${ }^{25}$ Moreover, only $<5 \%$ reported availability of enough soap, water, and hand sanitizers even at healthcare facilities. ${ }^{25}$

KAP of HCWs and communities about COVID-19 and its prevention was associated with several factors. Among HCWs, younger age, ${ }^{26}$ having college level education, ${ }^{18,27}$ being a physician, ${ }^{18}$ owning TV/radio at home,${ }^{18}$ access for IPC training and guideline, ${ }^{26}$ prior knowledge about pandemic diseases, ${ }^{18}$ being urban resident, ${ }^{26}$ and social media use $^{26}$ were associated with better knowledge and favorable attitudes. Exposure to IPC-related training, having a better knowledge and a positive attitude about COVID-19, having a chronic medical illness, and being married were associated with better IPC practices. ${ }^{26,53}$ On the other hand, younger age, ${ }^{47}$ rural residency, working at low level healthcare facility, shortage of personal protective equipment (PPE), and high workload were associated with poor practice of infection prevention measures among HCWs. ${ }^{26}$

For the general public, younger age, ${ }^{50,55,56}$ urban residency, ${ }^{50}$ college level education, ${ }^{50,55,56}$ access to TV/ Radio and internet, ${ }^{20,56}$ having large family size, ${ }^{50,55}$ and having chronic medical illness ${ }^{56}$ were associated with good level of knowledge and favorable attitude for COVID-19 prevention. Similarly, high level of education, urban residency, female sex, older age, having a good knowledge and a positive attitude, intention to seek care, having a chronic medical condition, and perceived mortality were positively associated with good IPC practices. ${ }^{55,56,58,59}$ However, male sex, young age, lack of formal education, and rural residency were associated with poor intention to implement IPC practices. ${ }^{19,57}$

\section{Disease Epidemiology and Clinical Profile of the Cases}

Studies on disease epidemiology were mainly descriptive. Slow but sustained increase in the reported number of cases $^{31}$ and PCR test positivity rate ${ }^{30,61}$ were observed in the first six months of the outbreak. Serological studies done in $\mathrm{April}^{68}$ and May $2020^{34}$ showed that there was already a high community prevalence in cities (up to $9 \%$ ). Almost all of the studies showed that young men were affected more than women with median age of 34-36 years. ${ }^{31-33,61}$ Most of the COVID-19 patients in the country during the first two months of the outbreak were imported cases. ${ }^{32,33,61}$ In terms of geographic distribution, most cases were concentrated in the capital Addis Ababa and surrounding towns. ${ }^{31,61}$ Data regarding the overall fatality rate of the outbreak were difficult to obtain, however, the case fatality among admitted cases was reported to be $1.9 \%{ }^{33}$ Severity of the disease and COVID-19related deaths were reported to be higher in the elderly, ${ }^{32,63,65,66}$ those with diabetes, ${ }^{63,64,67}$ and those presenting with cough and dyspnea. ${ }^{62,65}$ Mortality among patients admitted with severe COVID-19 was very high $(33.3 \%)^{67}$ and outcome of intubated patients was reported to be very low (survival of $<20 \%$ ). ${ }^{33}$

\section{Mental Health Issues During COVID-I9 Pandemic}

The perceived psychological toll of the pandemic was reported to be very high among $\mathrm{HCWs},{ }^{36,51,70}$ college students, ${ }^{73}$ and the general public ${ }^{35,37,69,71,72}$ alike. Depression symptoms $(12.4-78.4 \%),{ }^{35,70}$ anxiety (36$81.9 \%),{ }^{35,70,73}$ and stress $(18-51.6 \%)^{35,36,69,70,73}$ were widely reported. Whether these were related to fear of COVID-19, economic difficulties during COVID or because of the underlying mental health problems remain to be known. Female sex,,$^{35,70,71,73}$ low-income status, ${ }^{35,37,71}$ and having a large family ${ }^{37,71}$ were associated with psychological problems.

In addition to moderate to severe psychological problems, HCWs reported a high rate of perceived vulnerability for COVID-19 infection ${ }^{29}$ and were worried about the risk of becoming infected with the virus and the risk of transmitting it to their families. ${ }^{60}$ As a result, most (97\%) of the HCWs reported that they were not ready to give care for COVID-19 patients. $^{21}$

\section{Preparedness for COVID-19 Control}

Despite having a good level of awareness, $\mathrm{HCWs},{ }^{74,76}$ the healthcare system, ${ }^{76}$ and the general public ${ }^{77}$ were not prepared for the COVID-19 pandemic. Major reasons mentioned by HCWs were lack of training, critical shortage of PPE, lack of scientific evidence at hand, inability to access guidelines and recommendations, limited access for 
Table I Comparison of COVID-19-Related Articles from Ethiopia in the First Nine Months of the Pandemic with Other African Countries as of October 10, 2020

\begin{tabular}{|c|c|c|c|c|c|c|}
\hline Country & $\begin{array}{c}\text { Number of } \\
\text { Articles on } \\
\text { PubMed }\end{array}$ & $\begin{array}{c}\text { Date of First } \\
\text { COVID-19 } \\
\text { Report* }\end{array}$ & $\begin{array}{c}\text { Total Reported } \\
\text { COVID-19 } \\
\text { Cases* }\end{array}$ & $\begin{array}{c}\text { Total Reported } \\
\text { CoVID-19-Related } \\
\text { Deaths* }\end{array}$ & $\begin{array}{c}\text { Total } \\
\text { Population in } \\
\text { Millions** }\end{array}$ & $\begin{array}{l}\text { Death per } \\
\text { Million } \\
\text { Population }\end{array}$ \\
\hline Ethiopia & 115 & I3-Mar-20 & 83,429 & 1277 & 115 & II.I \\
\hline Kenya & 145 & I3-Mar-20 & 41,158 & 760 & 54 & 14.17 \\
\hline Morocco & 191 & $02-M a r-20$ & $|49,84|$ & 2572 & 37 & 69.5 \\
\hline Nigeria & 353 & $28-F e b-20$ & 60,103 & 1115 & 206 & 5.4 \\
\hline Egypt & 537 & 14-Feb-20 & 104,387 & 6040 & 102 & 59.2 \\
\hline South Africa & 774 & 05-Mar-20 & 690,896 & 18,042 & 59 & 305.8 \\
\hline
\end{tabular}

Notes: * Obtained from daily COVID-19 report of respective countries, ** Obtained from Woldometer (https://www.worldometers.info/world-population/). ${ }^{83}$

literature, low local support, poor communication and collaboration between stakeholders, and fear of contracting the infection. ${ }^{39,74-76}$

\section{Impacts on Essential Healthcare}

Few studies tried to assess the impact of COVID-19 control actions on access and delivery of essential healthcare services. Maternal and child health were major areas of focus for most of the studies. Compared with prior years, there were reductions during the first three months of COVID-19 in Ethiopian antenatal care, institutional deliveries, safe abortion care, family planning utilization, and neonatal admissions. ${ }^{40,41,79-81}$ A modeling study based on these findings indicated an excess of at least 10,252 under-five deaths, 379-4038 maternal deaths, and 1673-13,294 stillbirths during the first few months of the outbreak. Such humanitarian crisis attributable to disruption of the healthcare system was more than the mortality caused by the pandemic itself. ${ }^{81}$ There were also disruptions in the care of patients with chronic non-communicable diseases such as hypertension and diabetes. ${ }^{78}$ Emergency medical services including emergency surgeries have also shown significant decline during the first three months of the outbreak. ${ }^{41}$

Fear of acquiring the infection, ${ }^{78,79}$ service interruptions, and restrictions of movement ${ }^{78}$ were mentioned as major reasons for disruption of essential healthcare services.

\section{Violence Against Women During COVID-19 Lockdown in Ethiopia}

One study ${ }^{42}$ tried to assess if there was an increase in violence against women during COVID-19 pandemic. The prevalence of intimate partner violence was reported to be $24.6 \%$. Psychological and physical violence were commonly reported among the affected women. Housewives, younger women $(<30$ years), women with arranged marriage, and women with a younger husband (31-40 years) were more likely to suffer from violence.

\section{Comparison of Peer-Reviewed Articles from Ethiopia Against Highly Affected Countries in Africa}

In order to assess the level of scientific evidence generated from Ethiopia, we also tried to compare peerreviewed articles on PubMed as of October 10, 2020. Accordingly, as compared with five other highly affected African countries, Ethiopia had the fewest peerreviewed articles on PubMed (115) compared with other countries; South Africa (774) had the highest number of articles (Table 1).

\section{Timeline of COVID-19 Outbreak and Counteractions Taken in Ethiopia}

We were also interested in comparing actions to curb the pandemic against the patterns of the outbreak. From this evaluation, we found that most of the actions were taken during the first three months of the outbreak when the rate of the disease transmission was low. These actions gradually declined and most of the restrictions were relaxed in September when the test positivity rates and daily reported number of cases were high (Figure 2). Moreover, the actions taken did not seem to be guided by the pattern of the outbreak and available local scientific evidence. For instance, during the period of March to June 2020, reported cases were predominantly imported ${ }^{32,33,61}$ and concentrated in and around Addis Ababa. ${ }^{31,61}$ However, no action was tailored to address the geographic distribution of the outbreak and pattern of spread. Instead, blanket restrictions were put in place for the whole 


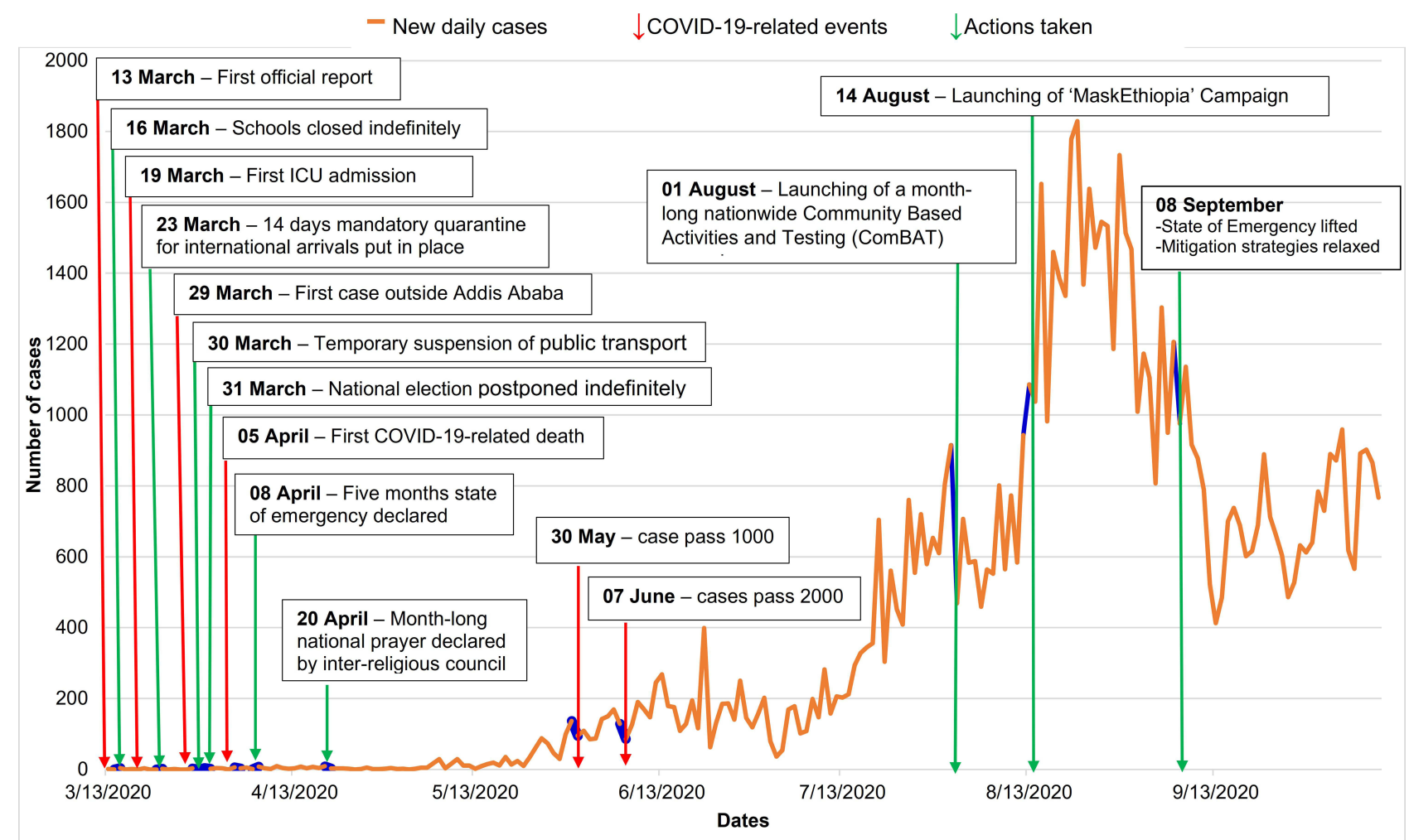

Figure 2 COVID-19 outbreak timeline in Ethiopia and actions taken to curb the pandemic. The figure was constructed based on information released on different occasions by COVID-19 pandemic preparedness and response weekly bulletin (Ethiopia Public Health Institute) and Federal Ministry of Health of Ethiopia.

nation even when essential healthcare services were reported to be extremely compromised at primary care facilities and regional hospitals. ${ }^{40,41,78-81}$

\section{Discussion}

Ethiopia, like many African countries, implemented several measures to contain the spread of COVID-19 during the early months of the outbreak. ${ }^{82}$ The outbreak appeared to be well contained during this period. ${ }^{10}$ However, the impacts of the actions taken as well as the threat imposed by the virus were not properly evaluated. ${ }^{84,85}$ As a result, the country was not able to take a measured and tailored action to contain the pandemic. The actions put in place during the early months were gradually relaxed and almost completely lifted by the time the outbreak started to unfold.

Studies conducted soon after the first reported cases have shown good level of awareness ${ }^{19-23,28,43,45,48,49,73}$ and favorable attitudes $27,43,45,49,51,56$ by community and HCWs towards COVID-19 and its control. However, the IPC practices by HCWs and the community remained low. ${ }^{22,25,44,52,54-56,58,59}$ Adherence to social distancing and mask use by both HCWs and the general public was reported to be poor. ${ }^{23,28,29,45,47,56-58}$ Moreover, HCWs, the healthcare system in general, and the community were not prepared for COVID-19 pandemic. ${ }^{74,76,77}$ Lack of proper training and guidelines, critical shortage of PPE, lack of scientific evidence at hand, low local support, lack of proper communication and collaboration between stakeholders, and fear of contracting the infection were reported by the HCWs to be the major limiting factors. ${ }^{39,74-76}$

Though limited, the studies have clearly depicted that the collateral damage was felt more than the direct impacts of the outbreak during the first few months. Maternal health service utilization declined significantly compared with the previous months. ${ }^{40,41,79-81}$ Overt mental health issues such as anxiety, depression, and stress were also reported during the time. ${ }^{35-37,51,69-73}$

Evidence about the real pattern of the outbreak in Ethiopia is scarce due to limited testing capacity ${ }^{86}$ and lack of local scientific evidence. The outbreak unfolded at a slower rate than initially feared. Nevertheless, the number of cases and PCR test positivity rate showed steady increase after the first three months of the initial 
report. $^{30,31,61}$ Because most of the studies were limited to Addis Ababa, ${ }^{31-34,61,63-68}$ much cannot be said about the pattern of the outbreak in Ethiopia. These studies have shown a very high fatality rate among patients admitted

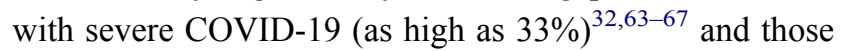
treated with mechanical ventilator ( $80 \%$ fatality). ${ }^{33}$

Research outputs on COVID-19 from Ethiopia were limited in both quantity and quality. For instance, the number of published articles containing COVID-19 and country name as of October 10, 2020 on PubMed yielded fewer publications than from other high COVID-19 burden countries in Africa - Egypt, Kenya, Nigeria, and South Africa. Furthermore, the existing research outputs were more of descriptive studies and focused mainly on human behavior. Important issues such as diagnostics, care of patients with the disease, and assessment of effectiveness of interventions were overlooked.

Looking closely at the actions taken by the country against the outbreak pattern, it is hard to explain the mitigation strategies scientifically. Most of the restrictions were put in place between March and April 2020, when the reported cases were very low and limited to imported cases. ${ }^{32,33,61}$ The restrictions were then relaxed after August 2020 when the outbreak was peaking (Figure 2). It is possible to speculate that the country tried to correct the panic actions taken before the outbreak kicked off and took a pragmatic action to minimize the collateral damages emanating from the restrictions. This might be intended to minimize the impact of the restrictions on Small and Medium Enterprises, which are critical to the country's economy. A similar pattern of initial prompt actions leading to economic difficulties forced many African countries to relax restrictions by the time the outbreak pattern was changing. ${ }^{87}$ This later led to major community outbreaks in many countries in the continent. ${ }^{88}$

However, such decisions should trade-off between the economy and the negative social impacts of downplaying the pandemic. This may ultimately lead to a sustained disease transmission and large community outbreaks. This has practically happened in Ethiopia in the first quarter of 2021 when the country registered the highest peak, test positivity rate, critical care admissions, and deaths due to COVID-19. ${ }^{89-91}$

The findings in our review indicate that understanding the social, economic, and environmental context of the country is important to design and implement public health interventions. Particularly in countries such as Ethiopia, where multiple cultural factors, financial constraints, and health system challenges were documented as major barriers, ${ }^{92}$ public health interventions should be tailored to cultural and social contexts of the society.

\section{Strengths and Limitation}

We did a comprehensive assessment of studies conducted in Ethiopia on COVID-19. However, systematic analysis and presentation of the findings suffered from extreme heterogeneity of the findings. Besides, most of the included articles were not peer-reviewed and suffered from methodological problems and doubtful scientific validities. Furthermore, some of the manuscripts in pre-print versions during our review might have been peer-reviewed and published in much changed form after our submission.

\section{Conclusion}

Ethiopia, likely other African countries, might have avoided the feared COVID-19-related crisis. However, the true burden of the pandemic is likely to be underestimated due to limited testing and surveillance systems. The country might have been faced with the dilemma of balancing between minimizing the humanitarian crisis due to the pandemic and limiting the economic impact of the public health measures. The strategies taken to control the outbreak might have also suffered from lack of local scientific evidence, cultural conflicts, and political interference. Moreover, adopting interventions designed for settings with different cultural context, economic situations, and pandemic risk might have also resulted in low public trust.

Hence, countries such as Ethiopia should prepare themselves for future similar pandemics even more than countries with robust healthcare systems. They should put a system in place to anticipate, detect, and early control outbreaks. Actions that are based on local scientific evidence, culturally sensitive, and locally acceptable should be prioritized.

\section{Data Sharing Statement}

All data related with this review have been provided as Supplementary Material.

\section{Acknowledgments}

We would like to thank Teresa Perez and Marie-Catherine Rausch, Center for International Health, Ludwig Maximilian University of Munich for their administrative support.

\section{Author Contributions}

EKG, MS, and MTE conceptualized and designed the study. EKG and MTE developed the search and scoring criteria, and 
reviewed the articles. All authors made a significant contribution to the work reported, whether that is in the conception, study design, execution, acquisition of data, analysis and interpretation, or in all these areas; took part in drafting, revising or critically reviewing the article; gave final approval of the version to be published; have agreed on the journal to which the article has been submitted; and agree to be accountable for all aspects of the work.

\section{Funding}

This work was funded by the $\mathrm{CIH}^{\mathrm{LMU}}$ Center for International Health at Ludwig-Maximilians-University, supported by the DAAD with funds from the Federal Ministry for Economic Cooperation and Development (BMZ), Germany [Award/grant number - not applicable].

\section{Disclosure}

The authors declare no competing interests in this work.

\section{References}

1. Fauci AS. Infectious diseases: considerations for the 21 st century. Clin Infect Dis. 2001;32(5):675-685. doi:10.1086/319235

2. Benefits of sharing. Nature. 2016;530(7589):129. doi:10.1038/ $530129 \mathrm{a}$

3. Lucas-Dominguez R, Alonso-Arroyo A, Vidal-Infer A, AleixandreBenavent R. The sharing of research data facing the COVID-19 pandemic. Scientometrics. 2021;126:1-16.

4. Burki T. China's successful control of COVID-19. Lancet Infect Dis. 2020;20(11):1240-1241. doi:10.1016/S1473-3099(20)30800-8

5. Xu T-L, Ao M-Y, Zhou X, et al. China's practice to prevent and control COVID-19 in the context of large population movement Infect Dis Poverty. 2020;9(1):115. doi:10.1186/s40249-020-00716-0

6. Raposo VL. Can China's 'standard of care' for COVID-19 be replicated in Europe? J Med Ethics. 2020;46(7):451-454. doi:10.1136/ medethics-2020-106210

7. Van Damme W, Dahake R, Delamou A, et al. The COVID-19 pandemic: diverse contexts; different epidemics-how and why? $B M J$ Glob Health. 2020;5(7):e003098. doi:10.1136/bmjgh-2020-003098

8. Moradian N, Ochs HD, Sedikies C, et al. The urgent need for integrated science to fight COVID-19 pandemic and beyond. $J$ Transl Med. 2020;18(1):205. doi:10.1186/s12967-020-02364-2

9. Tolu LB, Ezeh A, Feyissa GT. How prepared is Africa for the COVID-19 pandemic response? The case of Ethiopia. Risk Manag Healthc Policy. 2020;13:771-776. doi:10.2147/RMHP.S258273

10. Wadvalla BA. How Africa has tackled covid-19. BMJ. 2020;370: $\mathrm{m} 2830$.

11. Gudina EK, Tesfaye M, Siraj D, Haileamilak A, Yilma D. COVID-19 in Ethiopia in the first 180 days: lessons learned and the way forward. Ethiop J Health Dev. 2020;34(4):6.

12. Earnshaw VA, Eaton LA, Kalichman SC, Brousseau NM, Hill EC, Fox AB. COVID-19 conspiracy beliefs, health behaviors, and policy support. Transl Behav Med. 2020;10(4):850-856. doi:10.1093/tbm/ ibaa090

13. Chowdhury AZ, Jomo KS. Responding to the COVID-19 pandemic in developing countries: lessons from selected countries of the global south. Development. 2020;163:1-10.
14. Dzinamarira T, Dzobo M, Chitungo I. COVID-19: a perspective on Africa's capacity and response. J Med Virol. 2020;92(11):2465-2472. doi:10.1002/jmv.26159

15. Misra A, Schmidt J, Harrison L. Combating COVID-19 with data: what role for national statistical systems? PARIS21 COVID-19 Res. 2020:1-13. Available form: https://paris21.org/sites/default/files/inline-files/COVID_ Policybrief_Full.pdf. Accessed October 27, 2021.

16. Arksey H, O'Malley L. Scoping studies: towards a methodological framework. Int J Soc Res Methodol. 2005;8(1):19-32. doi:10.1080/ 1364557032000119616

17. Tricco AC, Lillie E, Zarin W, et al. PRISMA extension for scoping reviews (PRISMA-ScR): checklist and explanation. Ann Intern Med. 2018;169(7):467-473. doi:10.7326/M18-0850

18. Abebe A, Mekuria A, Balchut A. Awareness of health professionals on COVID-19 and factors affecting it before and during index case in North Shoa Zone, Ethiopia, 2020. Infect Drug Resist. 2020;13:2979-2988. doi:10.2147/IDR.S268033

19. Mechessa DF, Ejeta F, Abebe L, et al. Community's knowledge of COVID-19 and its associated factors in Mizan-Aman Town, Southwest Ethiopia, 2020. Int J Gen Med. 2020;13:507-513. doi:10.2147/IJGM.S263665

20. Aweke Z, Jemal B, Mola S, Hussen R. Knowledge of COVID-19 and its prevention among residents of the Gedeo zone, South Ethiopia. Sources of information as a factor. Curr Med Res Opin. 2020;36 (12):1955-1960. doi:10.1080/03007995.2020.1835854

21. Jamie AH. Knowledge, attitude and practice of healthcare workers towards novel Corona Virus (COVID-19) in Jugal Hospital, Harari Regional State, Ethiopia. EC Nurs Healthcare. 2020;2(8):64-70.

22. Akalu Y, Ayelign B, Molla MD. knowledge, attitude and practice towards COVID-19 among chronic disease patients at Addis Zemen hospital, Northwest Ethiopia. Infect Drug Resist. 2020;13:1949-1960. doi:10.2147/IDR.S258736

23. Nigussie TW, Azmach NN. Knowledge, attitude and practice towards covid-19 among Arba Minch town, southern Ethiopia. Glob Sci J. 2020;8(6). Available form: https://www.researchgate.net/publication/ 343046917_Knowledge_Attitude_and_Practice_towards_COVID-19 among_Arba_Minch_Town_Residents_Southern_ Ethiopia\#fullTextFileContent. Accessed October 27, $202 \overline{1}$.

24. Kebede Y, Yitayih Y, Birhanu Z, Mekonen S, Ambelu A, Tu W-J. Knowledge, perceptions and preventive practices towards COVID-19 early in the outbreak among Jimma university medical center visitors, Southwest Ethiopia. PLoS One. 2020;15(5):e0233744. doi:10.1371/ journal.pone. 0233744

25. Jamie AH. Hand washing practices among health care workers in Jugal Hospital, Harar, Ethiopia, 2020: in the era of corona virus: Observational Study. J AntivirAntiretrovir. 2020;12(197):5-9.

26. Asemahagn MA. Factors determining the knowledge and prevention practice of healthcare workers towards COVID-19 in Amhara region, Ethiopia: a cross-sectional survey. Trop Med Health. 2020;48:72. doi:10.1186/s41182-020-00254-3

27. Kassie BA, Adane A, Tilahun YT, Kassahun EA, Ayele AS, Belew AK. Knowledge and attitude towards COVID-19 and associated factors among health care providers in Northwest Ethiopia. PLoS One. 2020;15(8):e0238415. doi:10.1371/journal.pone.0238415

28. Girma S, Alenko A, Agenagnew L. Knowledge and precautionary behavioral practice toward COVID-19 among health professionals working in public university hospitals in Ethiopia: a web-based survey. Risk Manag Healthc Policy. 2020;13:1327-1334. doi:10.2147/RMHP.S267261

29. Girma S, Agenagnew L, Beressa G, Tesfaye Y, Alenko A, Seale H. Risk perception and precautionary health behavior toward COVID-19 among health professionals working in selected public university hospitals in Ethiopia. PLoS One. 2020;15(10):e241101. doi:10.1371/journal.pone.0241101

30. Oladeji O, Oladeji B, Ismail AS, Abdi A. Application of call centre as COVID 19 alert and surveillance system in pastoralist communities of Somali Region of Ethiopia. J Adv Med Med Res. 2020;32 (13):23-28. doi:10.9734/jammr/2020/v32i1330549 
31. Abate L, Bekele A, Bedada B. Status of distribution of coronavirus disease (COVID-19) in Ethiopia within first three months. Acad J Res Sci Publ. 2020;2(15):156-166.

32. Teklu S, Sultan M, Azazh A, et al. Clinical and socio-demographic profile of the first 33 COVID-19 cases treated at dedicated treatment center in Ethiopia. Ethiop J Health Sci. 2020;30(5):645-652.

33. Gebremariam BM, Shienka KL, Kebede BA, Abiche MG. Epidemiological characteristics and treatment outcomes of hospitalized patients with COVID-19 in Ethiopia. Pan Afr Med J. 2020;37 (Suppl 1):7. doi:10.11604/pamj.supp.2020.37.1.24436

34. Kempen JH, Abashawl A, Suga HK, et al. SARS-CoV-2 serosurvey in Addis Ababa, Ethiopia. Am J Trop Med Hyg. 2020;103 (5):2022-2023. doi:10.4269/ajtmh.20-0816

35. Kassaw C. The magnitude of psychological problem and associated factor in response to COVID-19 pandemic among communities living in Addis Ababa, Ethiopia, March 2020: a Cross-Sectional Study Design. Psychol Res Behav Manag. 2020;13:631-640. doi:10.2147/ PRBM.S256551

36. Chekole YA, Yimer Minaye S, Mekonnen Abate S, Mekuriaw B. Perceived stress and its associated factors during COVID-19 among healthcare providers in Ethiopia: a Cross-Sectional Study. Adv Public Health. 2020;2020:5036861. doi:10.1155/2020/5036861

37. Kassaw C, Pandey D. The current mental health crisis of COVID-19 pandemic among communities living in Gedeo Zone Dilla, SNNP, Ethiopia, April 2020. J Psychosoc Rehabil Ment Health. 2021;8:1-5.

38. Kasahun GG, Kahsay GM, Asayehegn AT, Demoz GT, Desta DM, Gebretekle GB. Pharmacy preparedness and response for the prevention and control of coronavirus disease (COVID-19) in Aksum, Ethiopia; a qualitative exploration. BMC Health Serv Res. 2020;20 (1):913. doi:10.1186/s12913-020-05763-9

39. Mulu GB, Kebede WM, Worku SA, Mittiku YM, Ayelign B. Preparedness and responses of healthcare providers to combat the spread of COVID-19 among North Shewa Zone Hospitals, Amhara, Ethiopia, 2020. Infect Drug Resist. 2020;13:3171-3178. doi:10.2147/IDR.S265829

40. Tolu LB, Hurisa T, Abbas F, Daba M, Nigatu B, Prager S. Effect of COVID-19 pandemic on safe abortion and contraceptive services and mitigation measures: a case study from a tertiary facility in Ethiopia. Ethiopian J Reprod Health. 2020;12(3):51-57.

41. Abdela SG, Berhanu AB, Ferede LM, van Griensven J. Essential healthcare services in the face of COVID-19 prevention: experiences from a referral hospital in Ethiopia. Am J Trop Med Hyg. 2020;103 (3):1198-1200. doi:10.4269/ajtmh.20-0464

42. Gebrewahd GT, Gebremeskel GG, Tadesse DB. Intimate partner violence against reproductive age women during COVID-19 pandemic in northern Ethiopia: a community-based cross-sectional study. Reprod Health. 2020;17:152. doi:10.1186/s12978-020-01002-w

43. Feleke DG, Tassew SF, Chanie ES. Assessment of knowledge, attitude and associated factors toward COVID-19 among nurses who work in South Gondar Zone, Hospitals, Northwest Ethiopia 2020, Institution-based cross-sectional Study. Res Sq. 2020. doi:10.21203/ rs.3.rs-68848/v2

44. Emiru TD, Birlie TA, Tasew SF, Amare AT, Tibebu NS, Tiruneh CM. Assessment of knowledge, practice and associated factors towards prevention of novel corona virus among clients attending at debre tabor general hospital Debre Tabor Town, North West Ethiopia, 2020: Institutional Based Cross-Sectional Study. SSRN Electron J. 2020. doi:10.2139/ssrn.3667842

45. Aynalem YA, Akalu TY, Gebresellassie B, Sharew NT, Shiferaw WS. Assessment of undergraduate student knowledge, practices, and attitude towards COVID-19 in Debre Berhan University, Ethiopia. Res Sq. 2020. doi:10.21203/rs.3.rs-28556/v1

46. Gelaw AB, Andargie SA. Assessment on awareness towards preventive measures of COVID-19 in Sheka, Ethiopia: community based cross-sectional Study. Res Sq. 2020. doi:10.21203/rs.3.rs-30820/v2
47. Hailu W, Derseh L, Hunegnaw MT, Tesfaye T, Abebaw D. Compliance, barriers, and facilitators to social distancing measures for prevention of COVID-19 in Northwest Ethiopia, 2020. Res Sq. 2020. doi:10.21203/rs.3.rs-68688/v1

48. Tsegaye D, Shuremu M, Oljira D, Dubale S, Befekadu G, Bidira K. Knowledge and preventive practices towards Covid-19 and associated factors among healthcare workers in selected health facilities of Illu Aba Bor and Buno Bedelle Zones, Southwest Ethiopia. Res Sq. 2020. doi:10.21203/rs.3.rs-49537/v2

49. Jemal B, Ferede ZA, Mola S, et al. Knowledge, attitude and practice of healthcare workers towards COVID-19 and its prevention in Ethiopia: a multicenter study. Res Sq. 2020. doi:10.21203/rs.3.rs-29437/v1

50. Tadesse AW, Melese N, Eshetie S, Chane M, Ali A. Knowledge, attitude, and practice and associated factors towards COVID-19 among college students in Amhara Region, Ethiopia; A Cross-Sectional Study. Res Sq. 2020. doi:10.21203/rs.3.rs-38099/v1

51. Tadesse DB, Tukue GG, Demoz GT. Knowledge, attitude, practice and psychological response toward COVID-19 among nurses during the COVID-19 outbreak in Northern Ethiopia. Res Sq. 2020. doi:10.21203/rs.3.rs-26236/v1

52. Defar A, Molla G, Abdella S, et al. Knowledge, practice and associated factors towards the prevention of COVID-19 among high-risk groups: a cross-sectional study in Addis Ababa, Ethiopia. medRxiv. 2020. doi:10.1101/2020.08.14.20172429

53. Mersha A, Shibiru S, Girma M, et al. Health professionals practice and associated factors towards precautionary measures for COVID-19 pandemic in public health facilities of Gamo zone, southern Ethiopia: a cross-sectional study. medRxiv. 2020. doi:10.1101/2020.09.05.20188805

54. Negera E, Demissie TM, Tafess K. Inadequate level of knowledge, mixed outlook and poor adherence to COVID-19 prevention guideline among Ethiopians. bioRxiv. 2020. doi:10.1101/2020.07.22.215590

55. Ayele AD, Mihretie GN, Belay HG, Teffera AG, Kassa BG, Amsalu BT. Knowledge and practice to prevent against Corona Virus Disease (COVID-19) and its associated factors among pregnant women in Debre Tabor Town Northwest Ethiopia: a Community Based Cross-Sectional Study. Res Sq. 2020. doi:10.21203/rs.3.rs-50212/v1

56. Mola S, Aweke Z, Jemal B, et al. Magnitude and associated factors for attitude and practice of Southern Ethiopian residents toward COVID-19 and its preventions: a community based cross sectional study. Res $S q$. 2020. doi:10.21203/rs.3.rs-36120/v1

57. Dires A, Gedamu S, Getachew Y. Perception of COVID-19 prevention methods efficacy and intention to use among patients with chronic disease in Dessie Town, Northeast Ethiopia: a Multicentered Cross-sectional Study. Res Sq. 2020. doi:10.21203/rs.3.rs-73649/v1

58. Wondimu W, Ejigu AG, Mekonen MA, et al. Practice of coronavirus disease-19 prevention methods and associated factors in three zones of Southwest Ethiopia: community based cross-sectional study. Res Sq. 2020. doi:10.21203/rs.3.rs-84406/v1

59. Dagne H, Alemu KA, Dagnew B, et al. Prevention practice and associated factors of Coronavirus disease 2019 (COVID-19) outbreak among educated Ethiopians: an online based cross-sectional survey. Res Sq. 2020. doi:10.21203/rs.3.rs-34504/v1

60. Deressa W, Worku A, Abebe W, Gizaw M, Amogne W. Risk perceptions and preventive practices of COVID-19 among healthcare professionals in public hospitals in Addis Ababa, Ethiopia. medRxiv. 2020. doi: $10.1101 / 2020.10 .30 .20223180$

61. Mengesha CH, Liben F, Mogas SB. Confirmed COVID-19 infected cases in Ethiopia: a Descriptive Study. SSRN Electron J. 2020. doi:10.2139/ssrn.3605275

62. Leulseged T, Hassen I, Maru E, et al. Characteristics and outcome profile of hospitalized African COVID-19 patients: the Ethiopian Context. medRxiv. 2020. doi:10.1101/2020.10.27.20220640

63. Leulseged TW, Abebe KG, Hassen IS, et al. COVID-19 disease severity and determinants among Ethiopian patients: a study of the millennium COVID-19 care center. medRxiv. 2020. doi:10.1101/ 2020.10.09.20209999 
64. Leulseged T, Alemahu D, Hassen I, et al. Determinants of developing symptomatic disease in Ethiopian COVID-19 patients. medRxiv. 2020. doi:10.1101/2020.10.09.20209734

65. Leulseged TW, Hassen IS, Maru EH, et al. Determinants of time to convalescence among COVID-19 patients at millennium COVID-19 care center in Ethiopia: a prospective cohort study. medRxiv. 2020. doi:10.1101/:2020.10.07.20208413

66. Leulseged TW, Hassen IS, Edo MG, et al. Duration of supplemental oxygen requirement and predictors in severe COVID-19 patients in Ethiopia: a survival analysis. medRxiv. 2020. doi:10.1101/ 2020.10.08.20209122

67. Maru EH, Leulseged TW, Hassen IS, et al. Predictors of death in severe COVID-19 patients at millennium COVID-19 care center in Ethiopia: a Case-Control Study. medRxiv. 2020. doi:10.1101/ 2020.10.07.20205575

68. Alemu BN, Addissie A, Mamo G, et al. Sero-prevalence of anti-SARS-CoV-2 antibodies in Addis Ababa, Ethiopia. bioRxiv. 2020. doi:10.1101/2020.10.13.337287

69. Girma A, Ayalew E. Covid-19 related stress and coping strategies among adults with chronic disease in Southwest Ethiopia. medRxiv. 2020. doi:10.1101/2020.08.14.20174318

70. Jemal K, Senbeta B, Geleta TA, Awol M. COVID-19 pandemic and self-reported symptoms of depression, anxiety, and stress among health care workers in Ethiopia. Res Sq. 2020. doi:10.21203/rs.3.rs-62244/v1

71. Kassaw C. The psychological impact of COVID-19 pandemic among communities living in Dilla Town, Ethiopia. Preprints. 2020:2020060356. doi:10.20944/preprints202006.0356.v1

72. Ambelu A, Birhanu Z, Yitayih Y, et al. Psychological distress during the COVID-19 pandemic in Ethiopia: the need for equal attention of intervention. Res Sq. 2020. doi:10.21203/rs.3.rs-33408/v1

73. Tadesse AW, Mihret S, Biset G, Muluneh A. Psychological impacts of COVID-19 among college students in Dessie Town, Amhara Region, Ethiopia; Cross-sectional Study. Res Sq. 2020. doi:10.21203/rs.3.rs-38100/v1

74. Edae CK, Heyi CD. Assessment of preparedness and response of health professionals towards COVID-19 pandemic during early period in public hospitals in Oromia Regional State, Ethiopia. Preprints. 2020:2020080657. doi:10.1101/2020080657/v1

75. Deressa W, Worku A, Abebe W, Gizaw M, Amogne W. Availability of personal protective equipment and satisfaction of healthcare professionals during COVID-19 pandemic in Ethiopia. medRxiv. 2020. doi:10.1101/2020.10.30.20223149

76. Ambie MB, Belay HG, Sewyew DA. Preparedness and approaches of health care providers to tackle the transmission of COVID-19 among South Gondar Zone Hospitals, Amhara, Ethiopia. Res Sq. 2020. doi:10.21203/rs.3.rs-57926/v1

77. Addis Y, Abate D, Batista J. Social work responses and household-level determinants of coronavirus preparedness in rural Ethiopia. Res Sq. 2020. doi:10.21203/rs.3.rs-51668/v1

78. Ketema B, Kaba M, Addissie A, Kantelhardt EJ. Challenges and coping strategies in non-communicable disease management during COVID-19 in Addis Ababa, Ethiopia: a qualitative study. Res Sq. 2020. doi:10.21203/rs.3.rs-56009/v1

Risk Management and Healthcare Policy

\section{Publish your work in this journal}

Risk Management and Healthcare Policy is an international, peerreviewed, open access journal focusing on all aspects of public health, policy, and preventative measures to promote good health and improve morbidity and mortality in the population. The journal welcomes submitted papers covering original research, basic science, clinical \& epidemiological studies, reviews and evaluations,
79. Temesgen K, Wakgari N, Tefera B, et al. Maternal health care services utilization in the amid of COVID-19 pandemic in West Shoa Zone, Central Ethiopia. medRxiv. 2020. doi:10.1101/2020.10.09.20210054

80. Temesgen K, Workie A, Dilnessa T. The impact of COVID-19 infection on maternal and reproductive health care services in governmental health institutions of Dessie town, North-East Ethiopia. medRxiv. 2020. doi:10.1105/2020.09.20.20198259

81. Yigezu A, Mirkuzie AH, Misganaw A, et al. The indirect impact of COVID-19 pandemic on maternal and child mortality in Ethiopia: a Modelling Study. SSRN. 2020. doi:10.2139/ssrn.3694748

82. Zikargae MH. COVID-19 in Ethiopia: assessment of how the Ethiopian government has executed administrative actions and managed risk communications and community engagement. Risk Manag Healthc Policy. 2020;13:2803-2810. doi:10.2147/RMHP.S278234

83. Worldometer. World Population. Available from: (https://www.world ometers.info/world-population/) Accessed November 30, 2020.

84. McNamara J, Robinson EJZ, Abernethy K, et al. COVID-19, systemic crisis, and possible implications for the wild meat trade in Sub-Saharan Africa. Environ Resour Econ. 2020;76(4):1045-1066.

85. Zar HJ, Dawa J, Fischer GB, Castro-Rodriguez JA. Challenges of COVID-19 in children in low- and middle-income countries. Paediatr Respir Rev. 2020;35:70-74.

86. Mulu A, Bekele A, Abdissa A, et al. The challenges of COVID-19 testing in Africa: the Ethiopian experience. Pan Afr Med J. 2021;38:6. doi:10.11604/pamj.2021.38.6.26902

87. Ogundele OA. COVID-19 changing pandemic pattern: why sub-Sahara Africa should reassess the current response approach. Pan Afr Med J. 2020;35(Suppl 2):111. doi:10.11604/pamj.supp.2020.35.2.24921

88. Salyer SJ, Maeda J, Sembuche S, et al. The first and second waves of the COVID-19 pandemic in Africa: a cross-sectional study. Lancet. 2021;397(10281):1265-1275. doi:10.1016/S0140-6736(21)00632-2

89. National Public Health Emergency Operation Center (PHEOC) of Ethiopia. COVID-19 pandemic preparedness and response in Ethiopia weekly bulletin. Available from: https://ephi.gov.et/down load/pheoc/. Accessed June 20, 2021.

90. John Hopkins University. COVID-19 dashboard by the Center for Systems Science and Engineering (CSSE) at Johns Hopkins University. Available from: https://coronavirus.jhu.edu/map.html. Accessed June 20, 2021.

91. World Health Organization. WHO Coronavirus Disease (COVID-19) dashboard. Available from: https://covid19.who.int/table. Accessed June 20, 2021.

92. Boti Sidamo N, Hussen S, Shibiru T, et al. Exploring barriers to effective implementation of public health measures for prevention and control of COVID-19 pandemic in gamo zone of Southern Ethiopia: using a modified tanahashi model. Risk Manag Healthc Policy. 2021;14:1219-1232. doi:10.2147/RMHP.S297114 guidelines, expert opinion and commentary, case reports and extended reports. The manuscript management system is completely online and includes a very quick and fair peer-review system, which is all easy to use. Visit http://www.dovepress.com/testimonials.php to read real quotes from published authors.

\section{Dovepress}

